\title{
Accurate determination of damaged subsurface layers in machined Inconel 718
}

Heithem Touazine $^{1} \cdot$ Mohammad Jahazi $^{1} \cdot$ Philippe Bocher $^{1}$

Received: 12 March 2016 /Accepted: 7 June 2016

(C) Springer-Verlag London 2016 


\title{
Accurate determination of damaged subsurface layers in machined Inconel 718
}

\author{
Heithem Touazine $^{\text {a*}}$, Mohammad Jahazi ${ }^{\text {a }}$, Philippe Bocher ${ }^{\text {a }}$ \\ ${ }^{a}$ École de Technologie Supérieure, 1100 rue Notre Dame Ouest H3C1K3, Montréal, Canada \\ * Corresponding author. Tel.:+1 514-926-8701; E-mail address: \\ heithem.touazine.1@etsmtl.net
}

\begin{abstract}
The machining of high strength materials used in aeronautical applications generates damage on the subsurface layer which can significantly affect the fatigue life of the machined components. It is then important to distinguish between the damages due to machining from those caused by mechanical polishing operations used for sample observation. In this study, a new method is proposed to characterize and quantify properly the affected layer by machining and eliminate the impact from the defects originated during mechanical polishing. A protective layer of nickel coating was deposited on the machined surface. An optimum thickness of $100 \mu \mathrm{m}$ was determined for the nickel layer to avoid any damage to the subsurface layer during sample preparation. The subsurface layer was analyzed using an automatic Knoop microhardness machine, laser-digital microscope and Electron BackScatter Diffraction (EBSD) microscopy.
\end{abstract}

\section{Keywords}

Machining; microstructure; subsurface layers; damages; microhardness; deformed layer.

\section{Introduction}

Surface integrity after machining can be characterized by microhardness, affected subsurface layer, and machining induced damages. These characteristics are critical in determining the fatigue life of machined components [1-3]. For example, Guo and Schwach [4] reported the hardness of the subsurface layer affects the fatigue life of AISI 52100 steel after machining. Also, Zhou et al. [5] reported different types of defects such as cavities, carbides cracking and detachment from matrix, and cracks formed during machining. The same results have been reported by Zou et al. [6] after machining of NiCr20TiAl superalloy. In addition, Zhou et al. reported that the machining condition specially, tool wear increasing 
during machining can induce a sever plastic deformation and recrystallization in the subsurface and a degradation of the machined part quality [7].

Nickel-iron base superalloys are extensively used in aerospace turbines and turbine gas power generators because they present superior mechanical properties and corrosion resistance at high temperatures up to $650^{\circ} \mathrm{C}$ due to their microstructure [8]. A combination of the body-centered tetragonal $\mathrm{Ni}_{3} \mathrm{Nb}, \gamma$ ', precipitates and the face-centered cubic $\mathrm{Ni}_{3}(\mathrm{Al}, \mathrm{Ti})$, $\gamma^{\prime}$ precipitates distributed in the $\gamma$ matrix enables it to operate at a high temperatures. $\delta$ phase particles are the result of $\gamma$ " transformation to more stable state of $\mathrm{Ni}_{3} \mathrm{Nb}$ over long time exposure at temperatures above $650^{\circ} \mathrm{C}$. In addition, the microstructure contains $(\mathrm{Nb}, \mathrm{Ti}) \mathrm{C}$ carbides with orthorhombic structure, localized at grain boundaries, which inhibit grain growth at high temperatures thereby improving creep properties $[9,10]$.

However, the machining of Inconel 718 induces defects such us plastic deformation and microcracks $[5,6,8,11-15]$ in the subsurface layers, thereby affecting the fatigue life of machined components [16]. These discontinuities are localized in the first $20 \mu \mathrm{m}$ from the machined surface $[5,11]$, making the formal quantification of the affected subsurface layers difficult and delicate. Current literature has insufficient data on characterization methods of the affected subsurface area and often contributions from sample preparation are not distinguished from the actual damages caused by machining [6]. This may results on overestimation of the damage or considering damages due to sample preparation as those caused by machining. For example, Samuel [17] has reported that mechanical polishing induces defects such as plastic deformation and damages to the sample's edge. These defects can be interpreted as a result of machining but they are actually coming from mechanical polishing operation.

The present investigation focuses on the development of a new method to characterize the subsurface layers affected by machining and minimize the impact of sample preparation on the final results thereby providing an accurate quantitative estimation of the level of microstructural damage. The validity and accuracy of the proposed method are demonstrated by precisely measuring the width of the deformed layer and the morphology of the grains up to the surface of the machined samples using EBSD. 


\section{Experiments and characterization}

\subsection{Material and methods}

Heat treated machined Inconel 718 samples according to the standard heat treatment procedure AMS 5663 were used for the experiments. The material presents an ASTM grain size of 9.5 measured using the MIP image analysis software (Nahamin Pardazan Asia, www.metsofts.com). The chemical composition of the Inconel 718 used is presented in Table 1. Hard turning tests were carried out on a MAZAK-NEXUS CNC center. The workpiece has a diameter of $50 \mathrm{~mm}$. The hard turning was performed in two machined surfaces. In order to minimise distortion during cutting operation, Wire Electrical Discharge Machining W-EDM was performed using AgieCharmilles CUT $30 \mathrm{P}$ machine in order to separate the two machined surfaces as shown in the Fig. 1.

In order to investigate the subsurface layers and properly quantify the thickness of the deformed layer, an electrolytic etchant was developed in the present investigation. The solution consisted of $1 / 3 \mathrm{H}_{2} \mathrm{O}_{2}$ and $2 / 3$ of $\mathrm{HCl}$. The electroetching parameters were $3.5 \mathrm{~V}$ and 3 seconds contact time. The etchant solution allowed a clear revealing of all the microstructure elements such as: grain boundaries, carbides, $\delta$ phases, as well as $\gamma^{\prime}$ and $\gamma$ ', precipitates, as shown in Fig. 2 (a) and (b). An OLYMPUS LEXT OLS 4100 confocal microscope was used to assess the defects for the mirror polished samples and quantify the depth of deformed layers for the etched ones. In order to evaluate the microhardness and estimate the thickness of the softened layer in the subsurface, a Knoop microhardness matrix was performed with CLEMEX ST 2000 automatic microhardness tester using a load of 10 gF. EBSD analyses were carried out on a Hitachi SU-82 scanning electron microscope equipped with EBSD setups from Oxford Instrument.

Three machined samples were selected from a Design Of Experiment (DOE) using response surface methodology. The cutting parameters are specified in Table 2 together with the cutting forces as measured by Kistler dynamometer model 9121.

\subsection{Nickel coating device}

A layer of nickel was deposited on the machined surface using nickel electrodes, a DC generator and a Watts solution as shown in the Fig. 3 (a). The coating parameters were optimized in order to achieve a $100 \mu \mathrm{m}$ thin layer, as it was found that thickness below 100 $\mu \mathrm{m}$ was not sufficient in holding on the machined surface during the mechanical polishing 
stages. The optimum coating parameters were determined to be $3 \mathrm{~mA} / \mathrm{dm}^{2}, 1$ hour and $45^{\circ} \mathrm{C}$ of current density, coating time, and temperature, respectively. Throughout the study, both the cutting (perpendicular to the feed direction) and feeding directions (parallel to the feed direction) were coated with the $100 \mu \mathrm{m}$ nickel layering and analyzed in both directions as shown in the Fig. 3 (b). It must be noted that the optimum conditions also allowed producing very fine nickel particles that took the form of the surface very precisely, thereby covering and protecting even very small defects.

\section{Results and discussion}

\subsection{Advantages of nickel coating protection}

Major defects can be found on the surface prepared with no nickel coating as revealed in the images in Fig. 4, where defects can be observed along both cutting and feeding directions. The samples prepared with the protective nickel layer did not display such a large quantity of defects as shown in the Fig. 5 (a), (b), (c) and (d). Defects due to sample preparation originate from the effect of the force applied to the sample edges during polishing which may result for example, in carbide detachment and ultimately to microcracks.

In order to test the effect of surface protection on microhardness, Knoop microhardness matrix was performed as shown in the Fig. 6 on coated and uncoated surfaces machined under similar conditions. The measurements were applied on a cross section and followed the feeding and cutting directions from the affected surface to the bulk material. The indentations were applied at a distance of about $5 \pm 1 \mu \mathrm{m}$ from the nickel coating. Three zones can be identified from the hardness profiles: a hard layer (zone 1); a soft layer (zone 2); and a region with significant variations and average values typical of the matrix (zone 3). The microhardness evolutions beneath the machined surface are represented in Fig. 7. It can be seen that hardness drops in the first $10 \mu \mathrm{m}$ for the cutting direction and in the first $15 \mu \mathrm{m}$ following the feed direction. In addition, microhardness values are always higher in the cutting direction than in the feeding direction. The thickness of the soft layer is about $23 \mu \mathrm{m}$ in the coated samples. This finding confirms that polishing operation without protecting the sample with an appropriate coating can introduce defects in the machined surface and particularly in the first few microns. These defects can relax compressive residual stresses and decrease hardness in the subsurface regions very close to the machined surface layer. In addition, polishing can deform the subsurface, about 10 to $15 \mu \mathrm{m}$ beneath the machined 
surface, resulting in curved edges and introducing more plastic deformation in the subsurface. By protecting sample's surface region with suitable coating, more control it becomes possible to precisely study surface damages due to machining and eliminate any influence of polishing operation on subsurface layer characteristics.

The occurrence of a hardened layer in the subsurface region of machined metallic materials has been previously reported by Zhou et al. [13] et Jawahir et al. [18]. Specifically, Pusavec et al. [14] reported the presence of a $40 \mu \mathrm{m}$ hardened layer in IN718 alloys due to severe machining. The microhardness profile performed in the work of Pusavec et al. [14] after machining showed that microhardness reaches a maximum value of $800 \mathrm{HV}$ on the machined surface exactly in the first $10 \mu \mathrm{m}$ beneath the surface. Afterwards, the microhardness decreases until reaching a hardness value of $500 \mathrm{HV}$ representing the matrix at a depth of 40 $\mu \mathrm{m}$. By comparison, in our work the maximum hardness values are in the first 12 to $20 \mu \mathrm{m}$ depending on the cutting conditions, followed by a softened layer. The main causes for the observed difference are probably: 1) the initial hardness of the Inconel 718 (the material used by Pusavec et al. is $9 \mathrm{HRC}$ softer than the one used in our research study) and 2) the difference in the geometry of the indenter used in each study. Therefore, machining can induce more plastic deformation in the subsurface. It must be also mentioned that different cutting conditions such as machining parameters and tool characteristics can impact hardness evolution in the subsurface layers and be an additional factor for the observed differences between our results and that of Pusavec et al. In addition, Umbrello reported that the thickness of hardened layer after dry machining of Inconel 718 was about $60 \mu \mathrm{m}$ to $130 \mu \mathrm{m}$ for a different cutting conditions [19]. In this region, the microstructure is severely deformed and therefore the dislocation density is very high. On the other hand, the presence of a softened layer below the hardened layer has been reported by Sharman et al. [20] and by Thakur et al. [21]. The phenomenon is likely to be due to both, the heat generated by friction during machining and/or the presence of tensile residual stresses in the subsurface [22]. It is important to note also that the low thermal conductivity of the Inconel $718\left(11 \mathrm{WmK}^{-1}\right)$ contributes to the thermal softening process by conserving the heat in the subsurface layers during machining. To the knowledge of the authors, no model or experimental results are available to quantify the contribution of each of the two above effects on the hardness profile.

\subsection{Measurement of the deformed layer}

Confocal microscope was used to measure the thickness of the deformed layer from the surface to the last distorted grain boundary and to the last defect as presented in Fig. 8. In 
order to have accurate results and a significant statistical analysis, at least 15 images at a magnification of $1000 \mathrm{X}$ were used for each machining condition. All values are presented with a confidence interval of $95 \%$ in Table 3 . The analysis of the obtained data shows that the thickness of deformed layer is different from both cutting and feeding directions, as displayed in the images for tests A, B and C in Fig. 9 (a) to (f).

Distorted grain boundaries can be clearly identified in the cutting direction, but evidences were also found in the feed direction. This is probably due to the different intensities of the cutting force components as reported in Table 1. The higher values of the cutting forces suggest that the deformation in the cutting direction (represented by radial and tangential force) is higher than in the feed direction (represented by the feed force), resulting in higher grain deformations and machining defects in the cutting direction.

\subsection{Quantification of affected machined layers}

The influence of machining conditions on the surface layer was quantified using the coated samples. The cutting and feed direction hardness profiles from the three selected cutting conditions are shown in Fig. 10 and the summary of the measured values from these graphs are reported in Table 3. For all conditions, it is confirmed that hardness is higher in the cutting direction than in the feed one. The hardness values following the cutting direction are higher than in the feed direction. This ascertainment could be explained as follows: As shown in Fig. 6 , first, the feed marks caused by the tool during machining are visible along the longitudinal section of the machined sample (i.e. feed direction). The distance between two feed marks' vertices is about few micrometers and it can be seen that the hardness at the bottom of the feed mark is higher than at its top. This is due to higher stress concentration and therefore more distortion in these regions (compare Fig. 9 (a), (c) and (e) with 9 (b), (d) and (f)). In contrast, in the cutting direction, which represents a cross section, it is not possible to distinguish the feed marks' vertices because the thickness of the abrasive cut-off wheel (few millimeters) is much higher than the distance between two vertices. Therefore, when measuring hardness in the feed direction, the obtained value will be a combination of the bottom (high hardness) and top (low hardness) regions of the feed marks resulting in a lower average value for the hardness in the cutting direction. Relative to the average matrix's hardness, the maximum hardness were found to be about $115 \mathrm{HK}$ higher, whereas the minimum ones were $43 \mathrm{HK}$ lower. The maximum hardness varies significantly from one cutting condition to the next (from 778 to $830 \mathrm{HK}$ ) while the lowest values stay quite similar 
(around $680 \mathrm{HK}$ ). The observed variations in the affected layers and the hardness of the softened and hardened layers are function of the cutting parameters. In fact, the depth of deformed layer and the microhardness values changed with changing cutting parameters. Published research on the effect of cutting parameters on surface integrity of machined part show that hardness increases with increasing cutting speed, feed rate and depth of cut [19, 20]. Furthermore, higher cutting speed, feed rate and depth of cut produce a deeper affected layer in the material. Finally, the magnitude of the cutting forces during is a critical factor when selecting machining parameters. The increasing of the cutting forces causes more deformation in depth, resulting in hardness increase $[23,24]$.

\subsection{Quantification and validation with EBSD misorientation maps}

In order to further study the limits of the deformed zones, EBSD maps were performed close to the edge of the machined surface. Full indexation was obtained for samples with the nickel coating allowing grain misorientations in the range of $1^{\circ}$ to $7^{\circ}$ to be displayed as illustrated Fig. 11 on the samples processed in test condition A. They are localized in a deformed layer with a thickness of around $7.8 \mu \mathrm{m}$ and $11.9 \mu \mathrm{m}$ following the feed and cutting direction, respectively. The results are consistent with the measurement of the deformed layer made by laser confocal microscope ( $6.3 \mu \mathrm{m}$ and $10.5 \mu \mathrm{m}$, respectively). It is also worth noting that in addition to revealing the deformed layer, the misorientation maps obtained from EBSD reveal that significant deformation are present further below the surface around carbides or twin boundaries. This is a confirmation of the particularities of these microstructures which are known to accumulate deformation in a strain field which will become potential fatigue nucleation sites [25-27].

\section{Conclusions}

A method for accurate characterization of damaged surface and subsurface layers using nickel coating was developed and validated on machined Inconel 718 samples. A combination of laser microscope, microhardness, and EBSD measurements were used to confirm and the validity and accuracy of the developed method. The results indicated that the deposition of the nickel layer prevents the generation of defects during sample preparation, allowing the identification of actual machining defects. Likewise, the protective nickel layer enables the proper measurements of the hardness close to the sample's edge. The hardness values revealed the presence of a work hardened and a softened layer below the surface after 
machining. The quantification of the deformed layer was validated by EBSD mapping. The latter technique revealed that large deformation can accumulate around carbides and twin boundaries at locations much deeper than the affected layer reported by the traditional hardness and optical measurement techniques.

\section{Acknowledgements}

National Science and Engineering Research Council NSERC as well as the industrial partners of the project: Pratt \& Whitney Canada and Heroux-Devtek are acknowledged for the support provided for the project CRIAQ MANU-510.

The authors are thankful for the support provided by Dr. Walid Jomaa for the sample machining. The first author also appreciates the efforts of Mr. Nathan Harris and Hadi Ghasemi Nanesa for proof-reading of the manuscript. 


\section{References}

1. Huang, Q. and J.X. Ren, Surface integrity and its effects on the fatigue life of the nickel-based superalloy GH33A. International Journal of Fatigue, 1991. 13(4): p. 322-326.

2. Guo, Y.B. and D.W. Schwach, An experimental investigation of white layer on rolling contact fatigue using acoustic emission technique. International Journal of Fatigue, 2005. 27(9): p. 1051-1061.

3. Sharman, A.R.C., et al., The effects of machined workpiece surface integrity on the fatigue life of $\gamma$ titanium aluminide. International Journal of Machine Tools and Manufacture, 2001. 41(11): p. 16811685.

4. Guo, Y.B. and D.W. Schwach, A fundamental study on the impact of surface integrity by hard turning on rolling contact fatigue. International Journal of Fatigue, 2006. 28(12): p. 1838-1844.

5. Zhou, J.M., V. Bushlya, and J.E. Stahl, An investigation of surface damage in the high speed turning of Inconel 718 with use of whisker reinforced ceramic tools. Journal of Materials Processing Technology, 2012. 212(2): p. 372-384.

6. Zou, B., et al., Study on surface damages caused by turning NiCr20TiAl nickel-based alloy. Journal of Materials Processing Technology, 2009. 209(17): p. 5802-5809.

7. Zhou, J.M., et al., Effects of Tool Wear on Subsurface Deformation of Nickel-based Superalloy. Procedia Engineering, 2011. 19: p. 407-413.

8. Klocke, F., W. König, and K. Gerschwiler, Advanced Machining of Titanium-and Nickel-Based Alloys, in Advanced Manufacturing Systems and Technology, E. Kuljanic, Editor. 1996, Springer Vienna. p. 721.

9. Kuo, C.M., et al., Aging effects on the microstructure and creep behavior of Inconel 718 superalloy. Materials Science and Engineering: A, 2009. 510-511: p. 289-294.

10. Chamanfar, A., et al., Microstructural characteristics of forged and heat treated Inconel-718 disks. Materials \& Design, 2013. 52: p. 791-800.

11. Zhou, J., et al., Analysis of Subsurface Microstructure and Residual Stresses in Machined Inconel 718 with PCBN and Al2O3-SiCw Tools. Procedia CIRP, 2014. 13: p. 150-155.

12. M'Saoubi, R., et al., Surface integrity analysis of machined Inconel 718 over multiple length scales. CIRP Annals - Manufacturing Technology, 2012. 61(1): p. 99-102.

13. Zhou, J.M., et al., Identification of Subsurface Deformation in Machining of Inconel 718. Applied Mechanics and Materials, 2011. 117-119: p. 1681-1688.

14. Pusavec, F., et al., Surface integrity in cryogenic machining of nickel based alloy-Inconel 718. Journal of Materials Processing Technology, 2011. 211(4): p. 773-783.

15. Touazine, H., M. Jahazi, and P. Bocher. Influence of Hard Turning on Microstructure Evolution in the Subsurface Layers of Inconel 718. in ASME 2014 International Mechanical Engineering Congress and Exposition. 2014. Montreal, Quebec, Canada.

16. Li, W., et al., Effect Tool Wear During End Milling on the Surface Integrity and Fatigue Life of Inconel 718. Procedia CIRP, 2014. 14: p. 546-551.

17. Samuels, L.E., Metallographic Polishing by Mechanical Methods, 4th Edition. 2003, ASM International.

18. Jawahir, I.S., et al., Surface integrity in material removal processes: Recent advances. CIRP Annals Manufacturing Technology, 2011. 60(2): p. 603-626.

19. Umbrello, D., Investigation of surface integrity in dry machining of Inconel 718. The International Journal of Advanced Manufacturing Technology, 2013. 69(9): p. 2183-2190.

20. Sharman, A.R.C., J.I. Hughes, and K. Ridgway, Workpiece Surface Integrity and Tool Life Issues When Turning Inconel 718 ${ }^{\mathrm{TM}}$ Nickel Based Superalloy. Machining Science and Technology, 2004. 8(3): p. 399-414.

21. Thakur, A., A. Mohanty, and S. Gangopadhyay, Comparative study of surface integrity aspects of Incoloy 825 during machining with uncoated and CVD multilayer coated inserts. Applied Surface Science, 2014. 320: p. 829-837.

22. Mary, C. and M. Jahazi, Linear Friction Welding of IN-718 Process Optimization and Microstructure Evolution. Advanced Materials Research, 2006. 15-17: p. 357-362.

23. Wang, F., et al., Experimental Study on Cutting Forces and Surface Integrity in High-Speed Side Milling of Ti-6Al-4V Titanium Alloy. Machining Science and Technology, 2014. 18(3): p. 448-463.

24. Sharman, A.R.C., J.I. Hughes, and K. Ridgway, An analysis of the residual stresses generated in Inconel 718 ${ }^{\mathrm{TM}}$ when turning. Journal of Materials Processing Technology, 2006. 173(3): p. 359-367.

25. Stinville, J.C., et al., High resolution mapping of strain localization near twin boundaries in a nickelbased superalloy. Acta Materialia, 2015. 98: p. 29-42.

26. Miao, J., T.M. Pollock, and J. Wayne Jones, Microstructural extremes and the transition from fatigue 
crack initiation to small crack growth in a polycrystalline nickel-base superalloy. Acta Materialia, 2012. 60(6-7): p. 2840-2854.

27. Miao, J., T.M. Pollock, and J. Wayne Jones, Crystallographic fatigue crack initiation in nickel-based superalloy René 88DT at elevated temperature. Acta Materialia, 2009. 57(20): p. 5964-5974. 


\section{List of Tables}

Table 1. Chemical composition of Inconel 718 (wt.\%)

\begin{tabular}{lccccccccccc}
\hline Element & $\mathrm{Ni}$ & $\mathrm{Fe}$ & $\mathrm{Cr}$ & $\mathrm{Nb}$ & $\mathrm{Ti}$ & $\mathrm{Mo}$ & $\mathrm{V}$ & $\mathrm{Al}$ & $\mathrm{Ta}$ & $\mathrm{Si}$ & $\mathrm{C}$ \\
\hline wt.\% & 52.97 & 18.51 & 18.36 & 4.47 & 1.02 & 3.14 & 0.09 & 0.39 & 0.22 & 0.22 & 0.07
\end{tabular}

Table 2. The different measured cutting force components according to the selected tests

\begin{tabular}{lcccccc}
\hline Test & $\begin{array}{c}\text { Cutting } \\
\text { speed } \\
(\mathrm{m} / \mathrm{min})\end{array}$ & $\begin{array}{c}\text { Feed rate } \\
(\mathrm{mm} / \mathrm{rev})\end{array}$ & $\begin{array}{c}\text { Depth of cut } \\
(\mathrm{mm})\end{array}$ & $\begin{array}{c}\text { Radial force } \\
(\mathrm{N})\end{array}$ & $\begin{array}{c}\text { Feed } \\
\text { force } \\
(\mathrm{N})\end{array}$ & $\begin{array}{c}\text { Tangential } \\
\text { force } \\
(\mathrm{N})\end{array}$ \\
\hline $\mathrm{A}$ & 58 & 0.142 & 0.265 & 106.1 & 66.0 & 169.4 \\
$\mathrm{~B}$ & 83 & 0.186 & 0.300 & 110.9 & 87.6 & 244.4 \\
$\mathrm{C}$ & 49 & 0.020 & 0.230 & 51.6 & 39.4 & 55.3 \\
\hline
\end{tabular}

Table 3. Quantification of the affected layer by machining

\begin{tabular}{ccccccc}
\hline Test & $\begin{array}{c}\text { Analysis } \\
\text { direction }\end{array}$ & $\begin{array}{c}\text { Deformed layer } \\
(\mu \mathrm{m})\end{array}$ & $\begin{array}{c}\text { Hard layer } \\
(\mu \mathrm{m})\end{array}$ & $\begin{array}{c}\text { Soft layer } \\
(\mu \mathrm{m})\end{array}$ & $\begin{array}{c}\text { Max. hardness } \\
(\mathrm{HK})\end{array}$ & $\begin{array}{c}\text { Min. hardness } \\
(\mathrm{HK})\end{array}$ \\
\hline \multirow{2}{*}{ A } & Feed & 6.3 & 13.5 & 15 & 802 & 680 \\
& Cutting & 10.5 & 20 & 23 & 830 & 677 \\
B & Feed & 7 & 10 & 15 & 804 & 676 \\
& Cutting & 10 & 15 & 20 & 812 & 691 \\
C & Feed & 9 & 8 & 10 & 778 & 680 \\
& Cutting & 9.4 & 12 & 13 & 800 & 678 \\
\hline
\end{tabular}




\section{List of Figures}

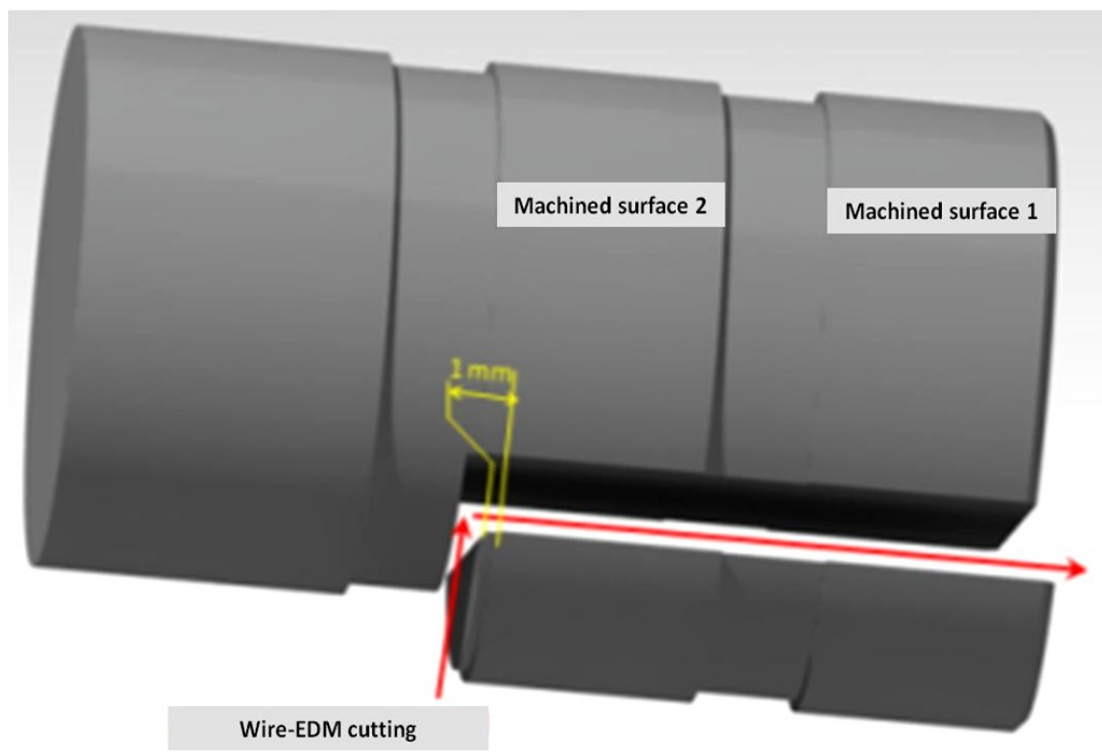

Fig. 1 Wire EDM cutting of the machined surfaces 


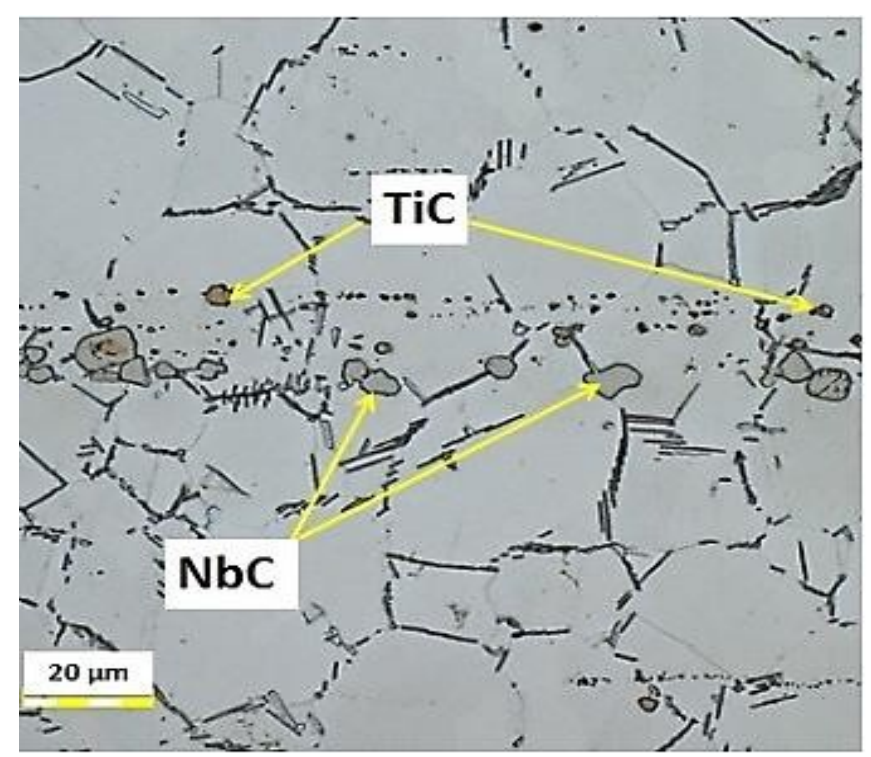

(a)

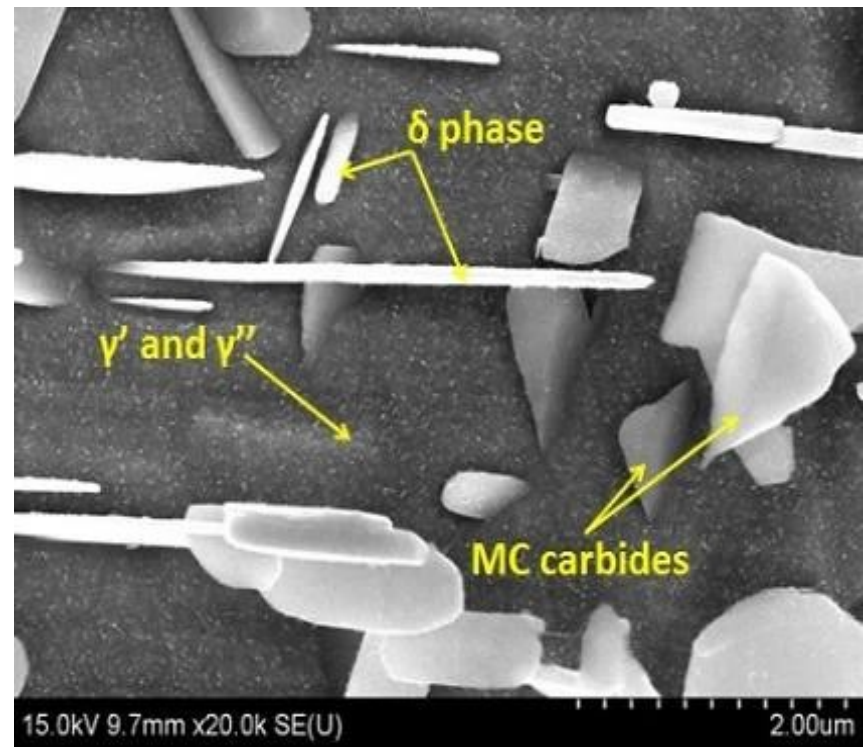

(b)

Fig. 2 Microstructure of Inconel 718: (a) optical microscope and (b) electronic microscope 


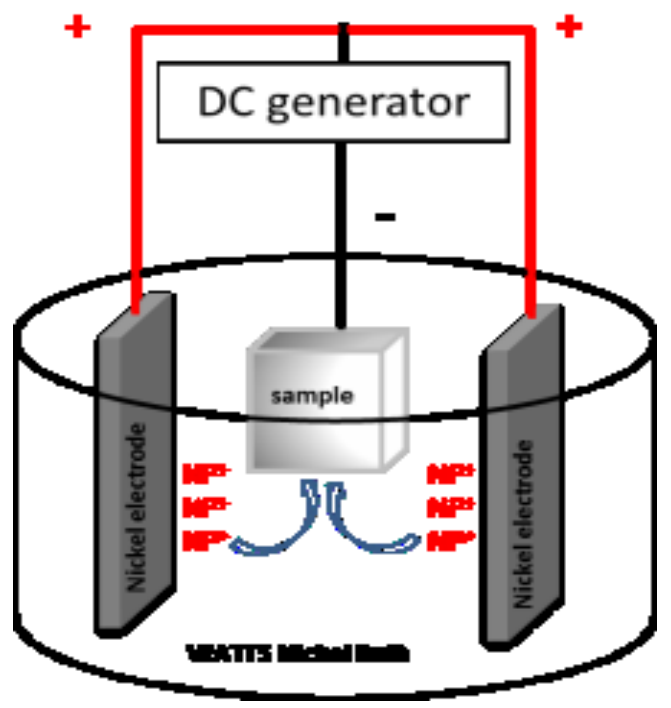

(a)

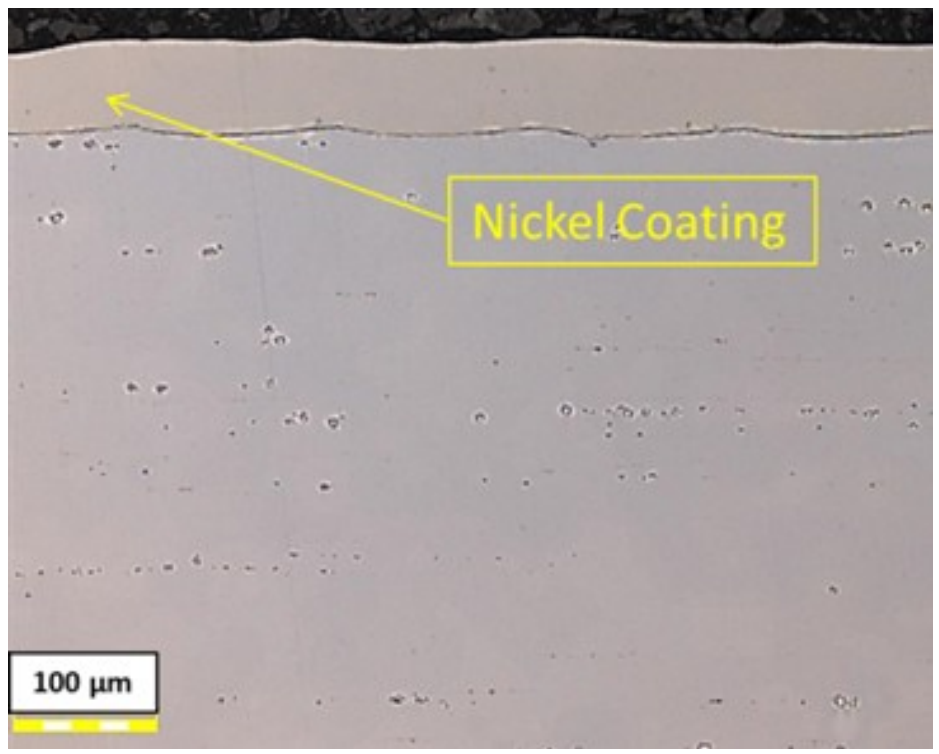

(b)

Fig. 3 Nickel coating method: (a) Nickel coating device (b) Nickel coating performed layer 


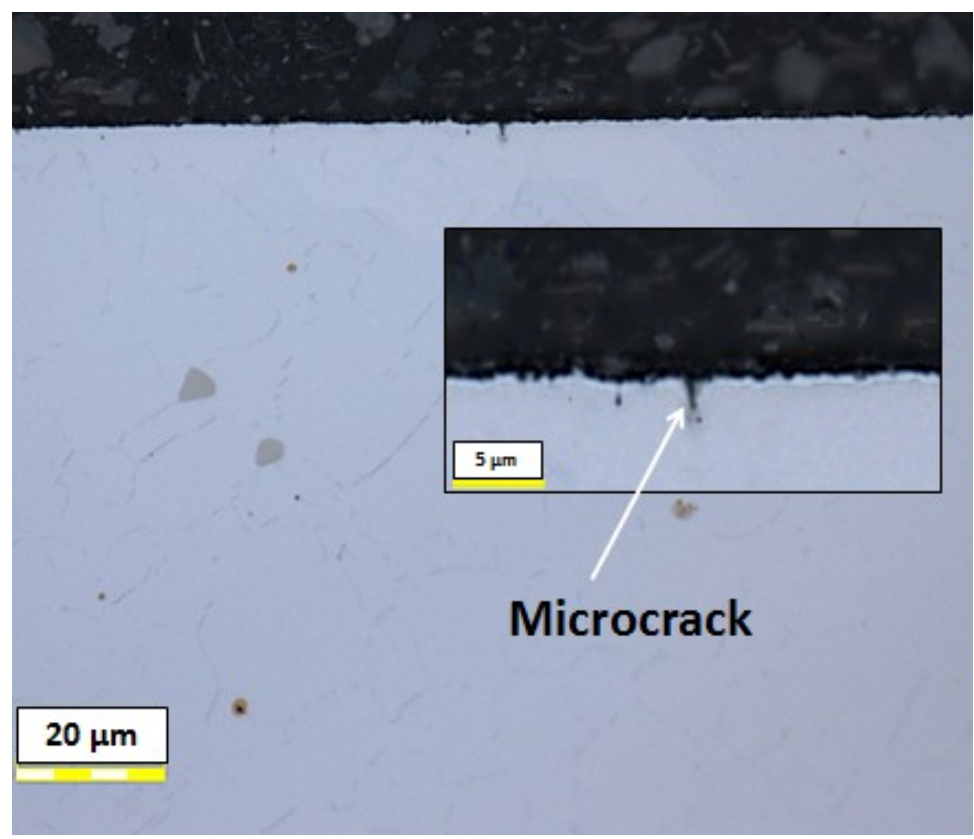

(a)

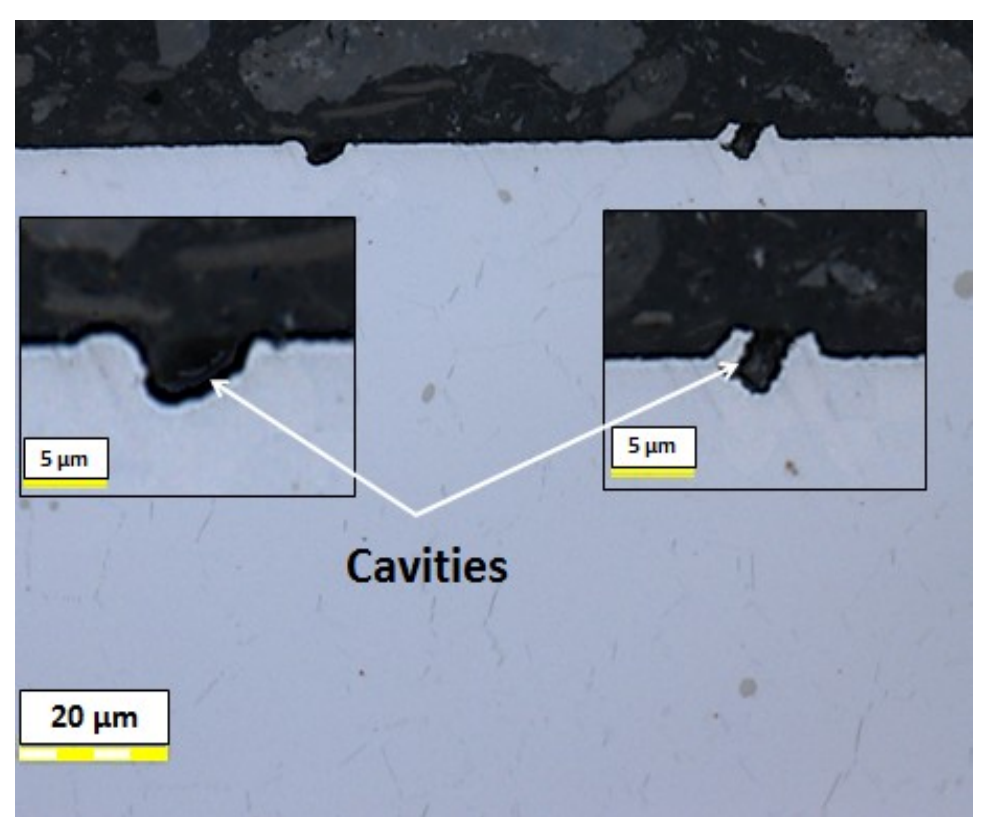

(b) 


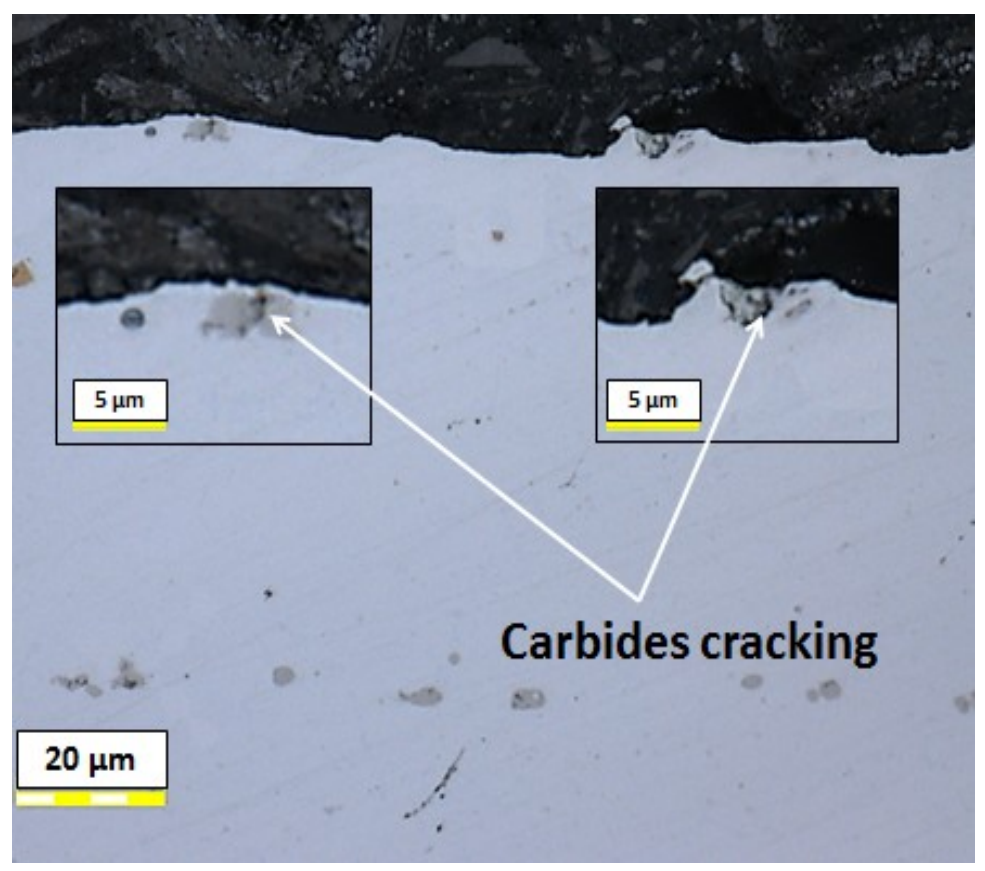

(c)

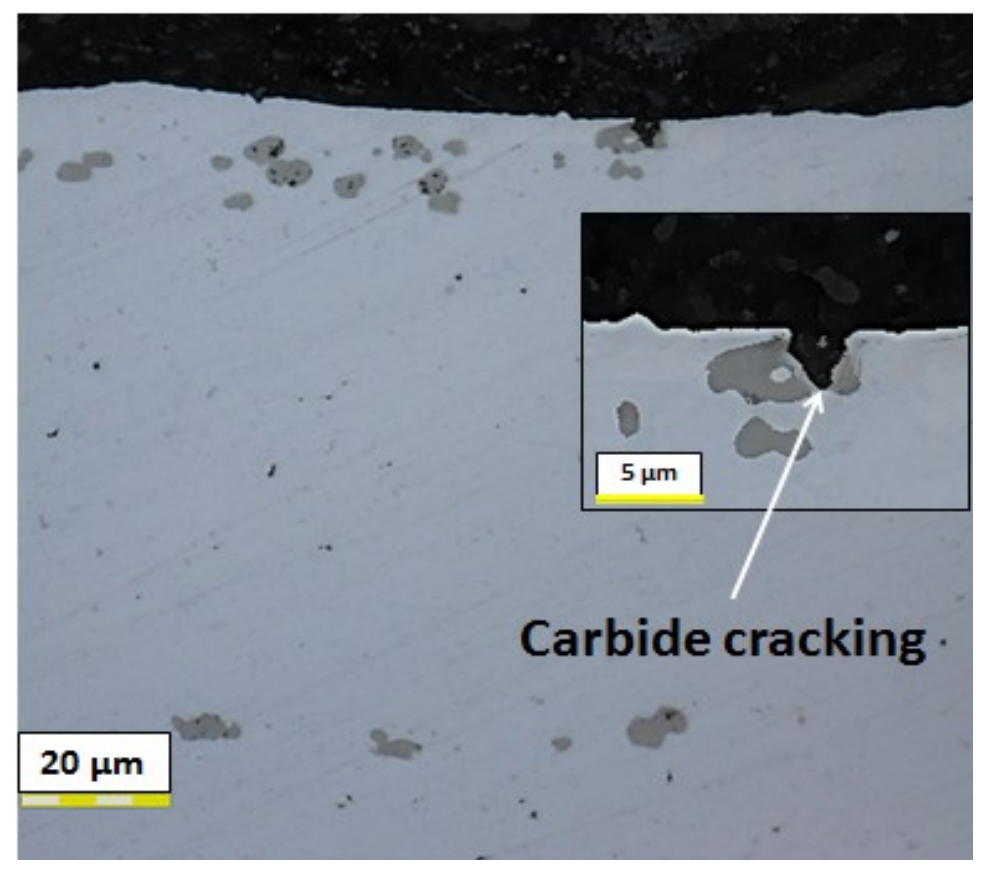

(d)

Fig. 4 Typical polishing defects and zooms related for the test A: (a), (b) following the cutting direction and (c), (d) following the feed direction 
Nickel coating

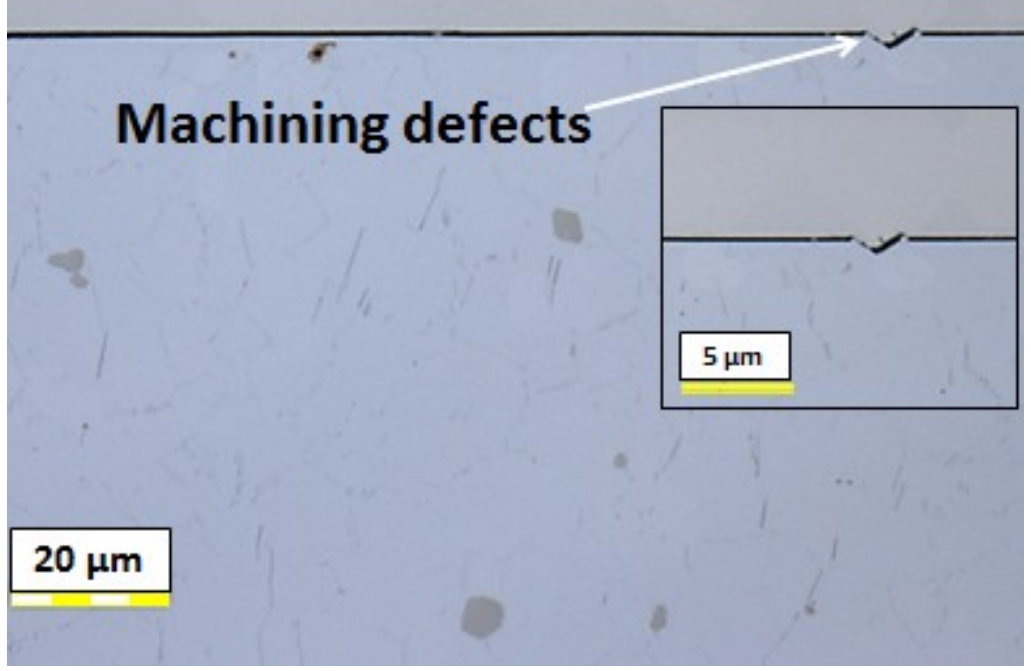

(a)

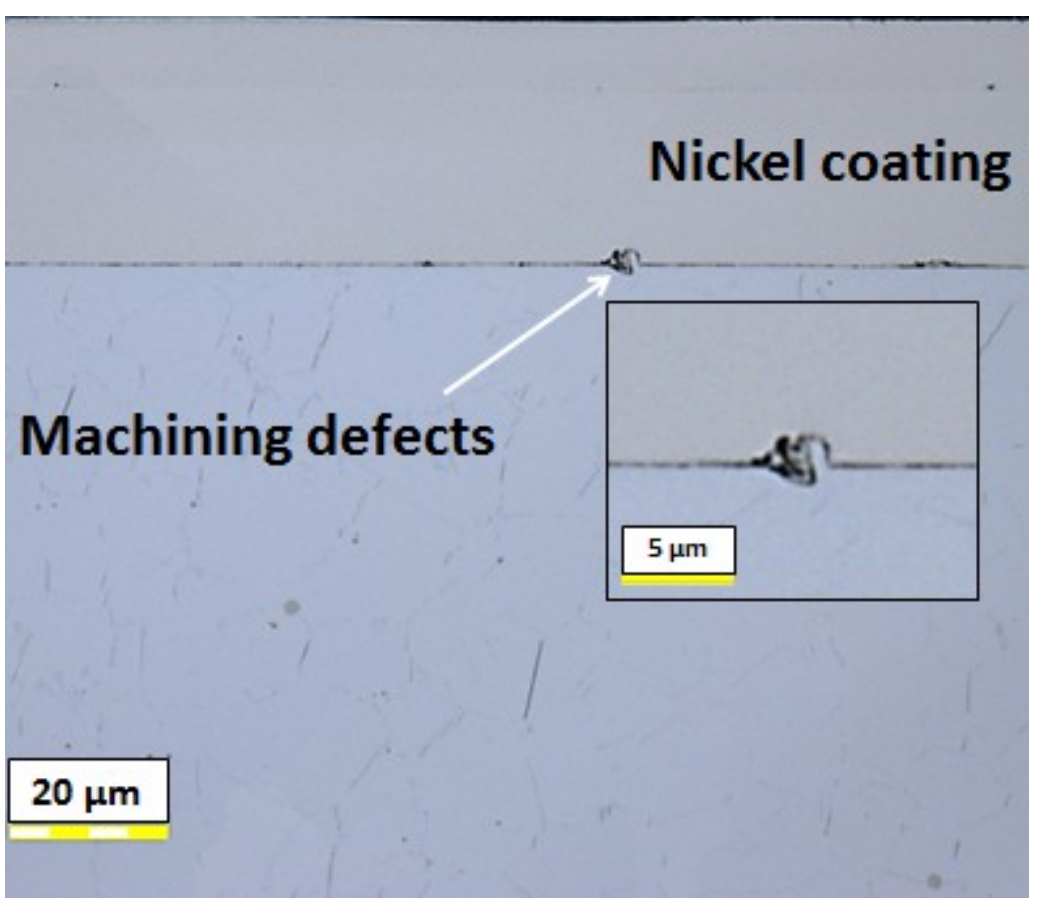

(b) 


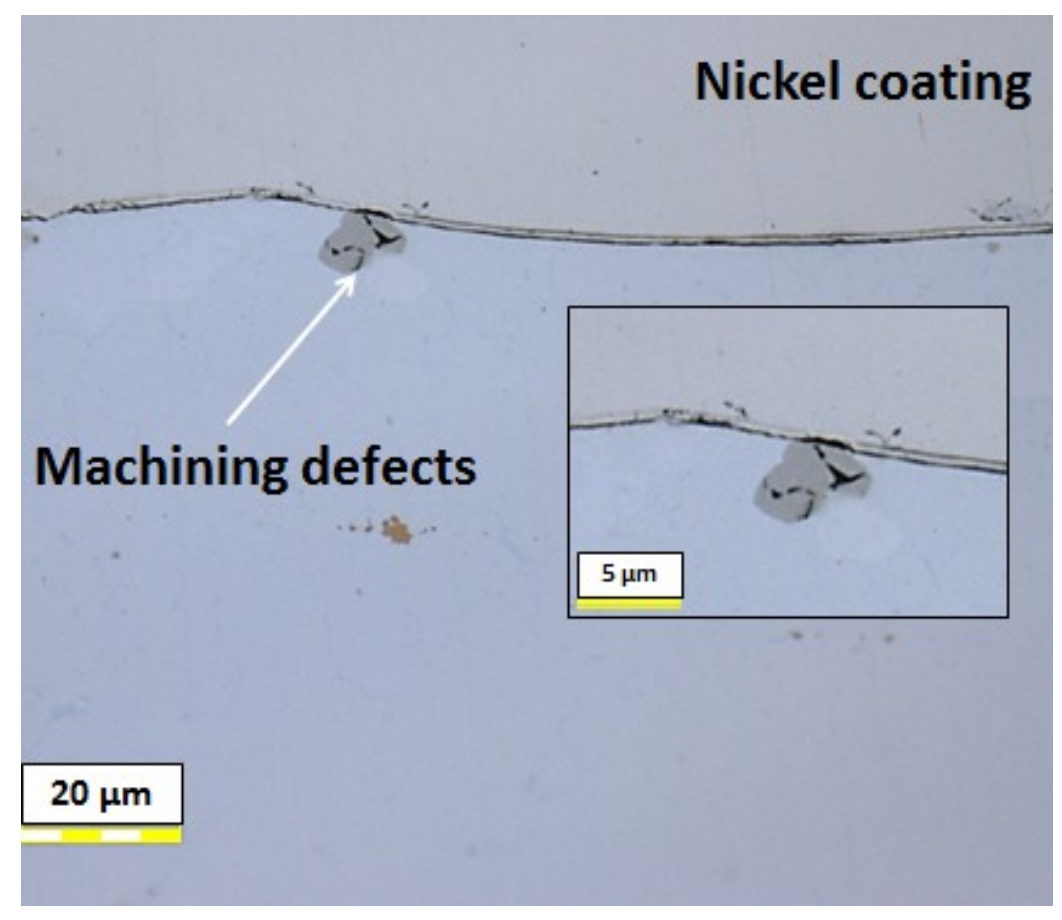

(c)

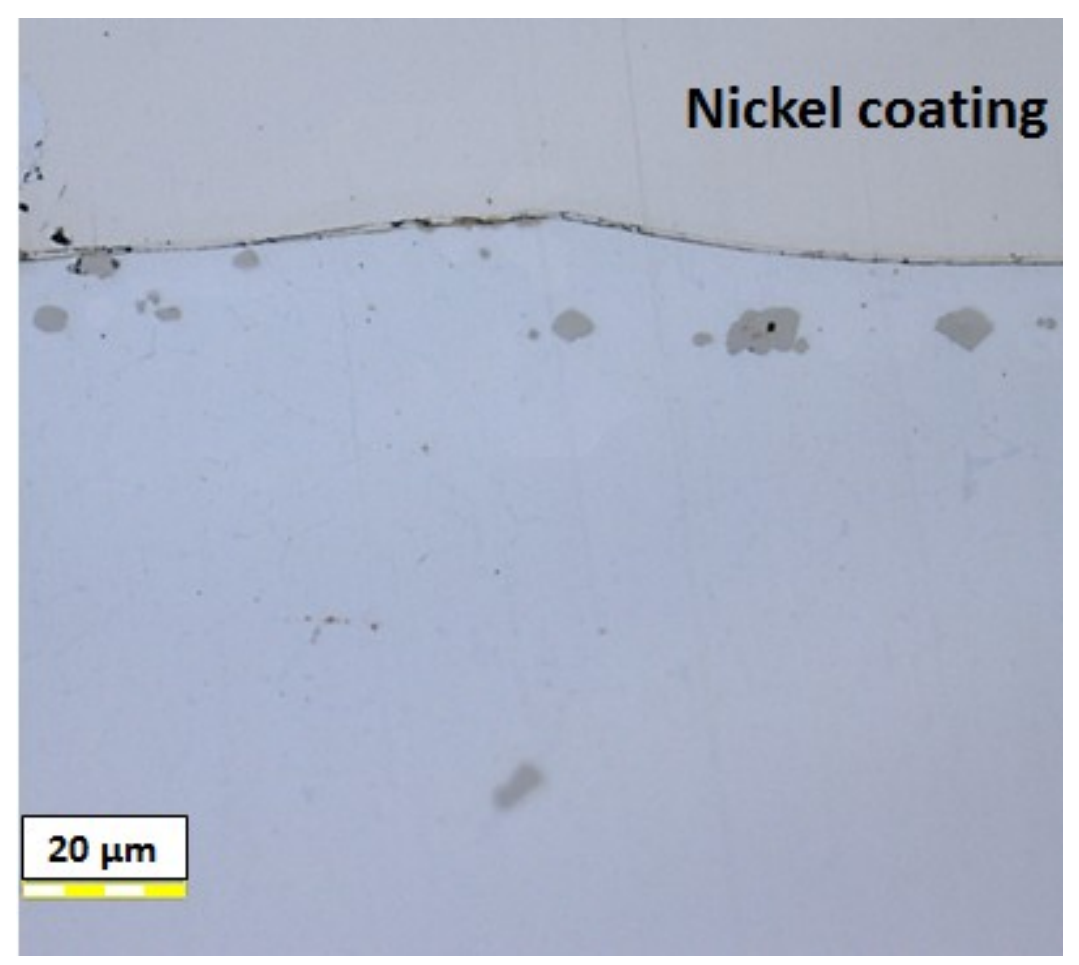

(d)

Fig. 5 Machining defects and related zooms: (a), (b) following the cutting and (b), (c) following the feed direction 


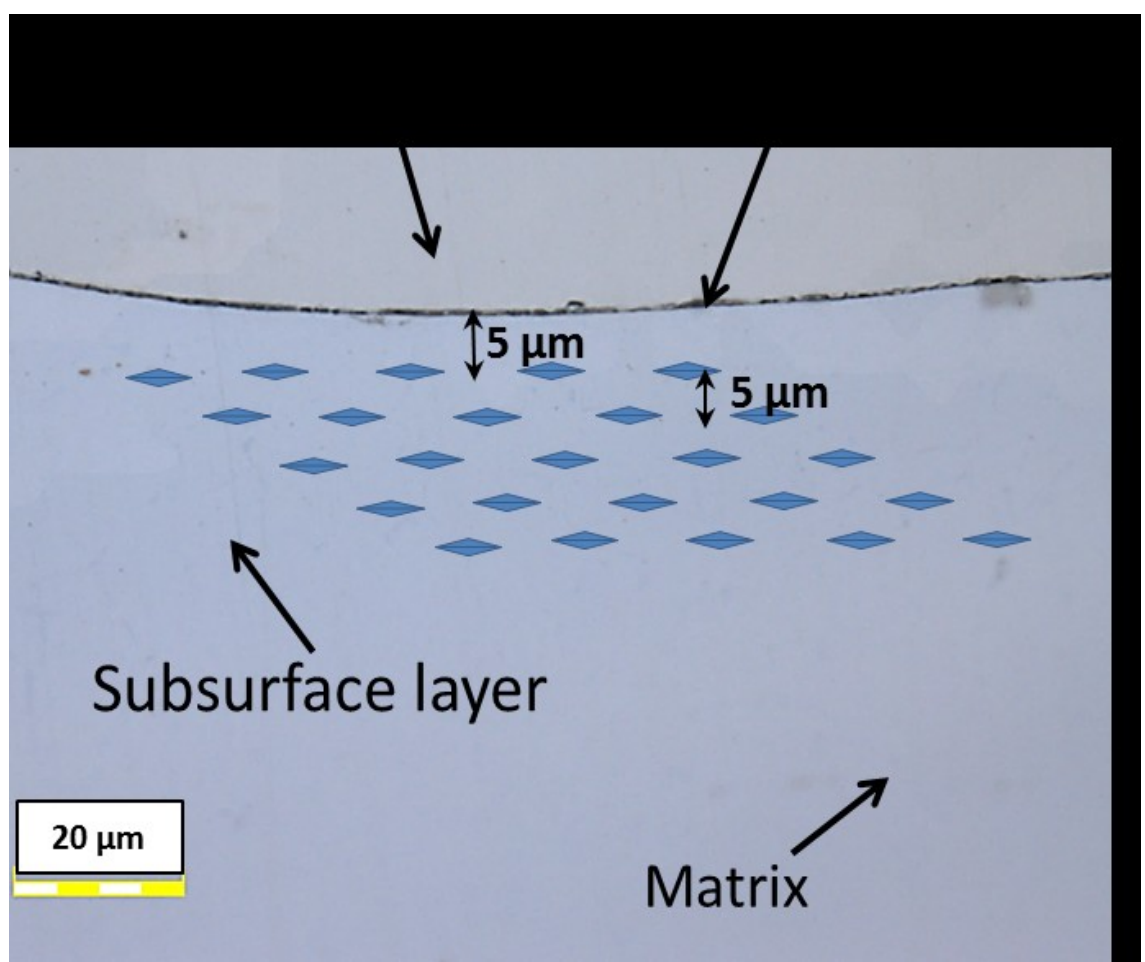

Fig. 6 Method used to characterize the softened layer using microhardness measurements

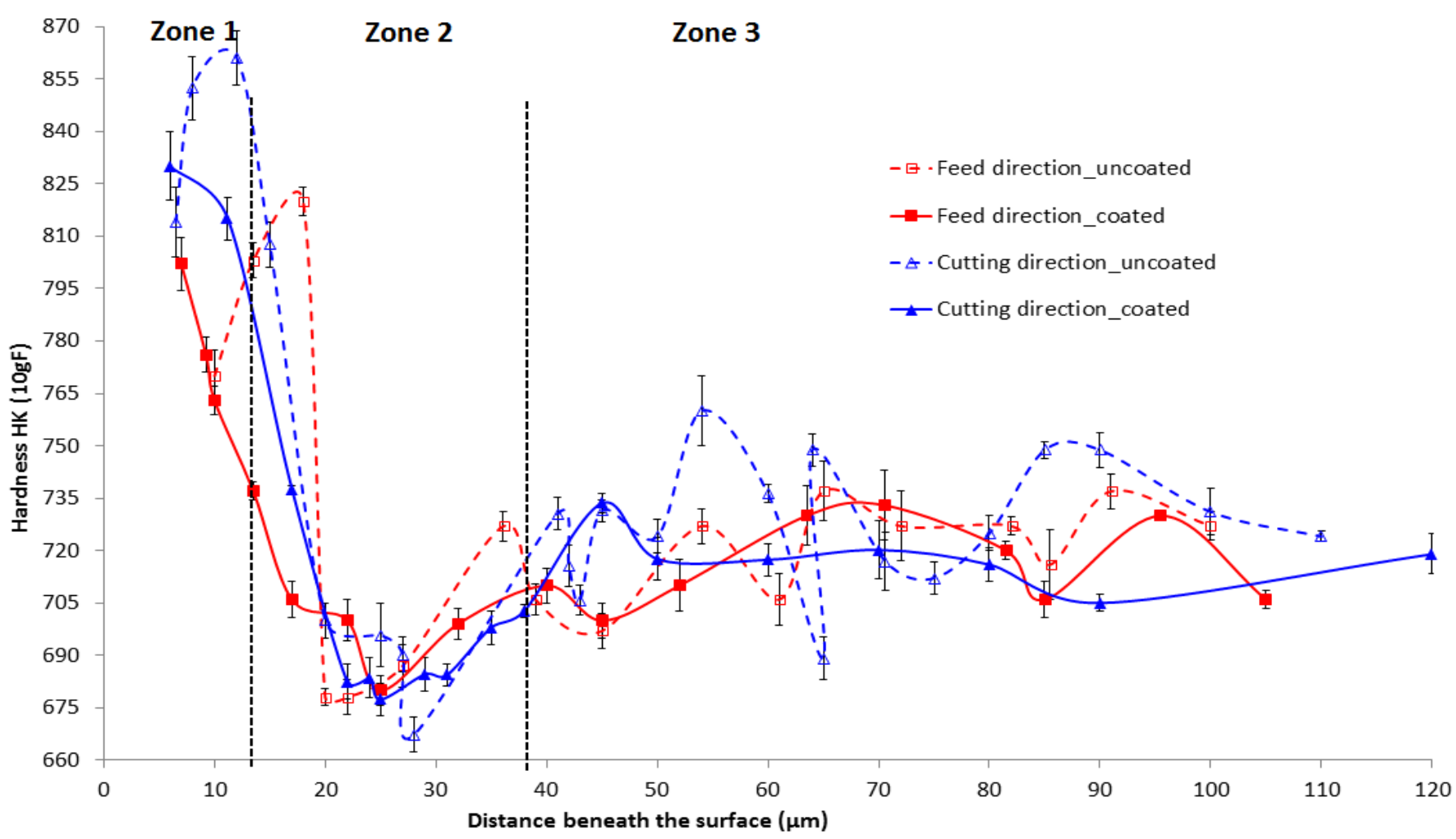

Fig. 7 Effect of the protective nickel coating on the values of microhardness beneath the machined surface for the test A 


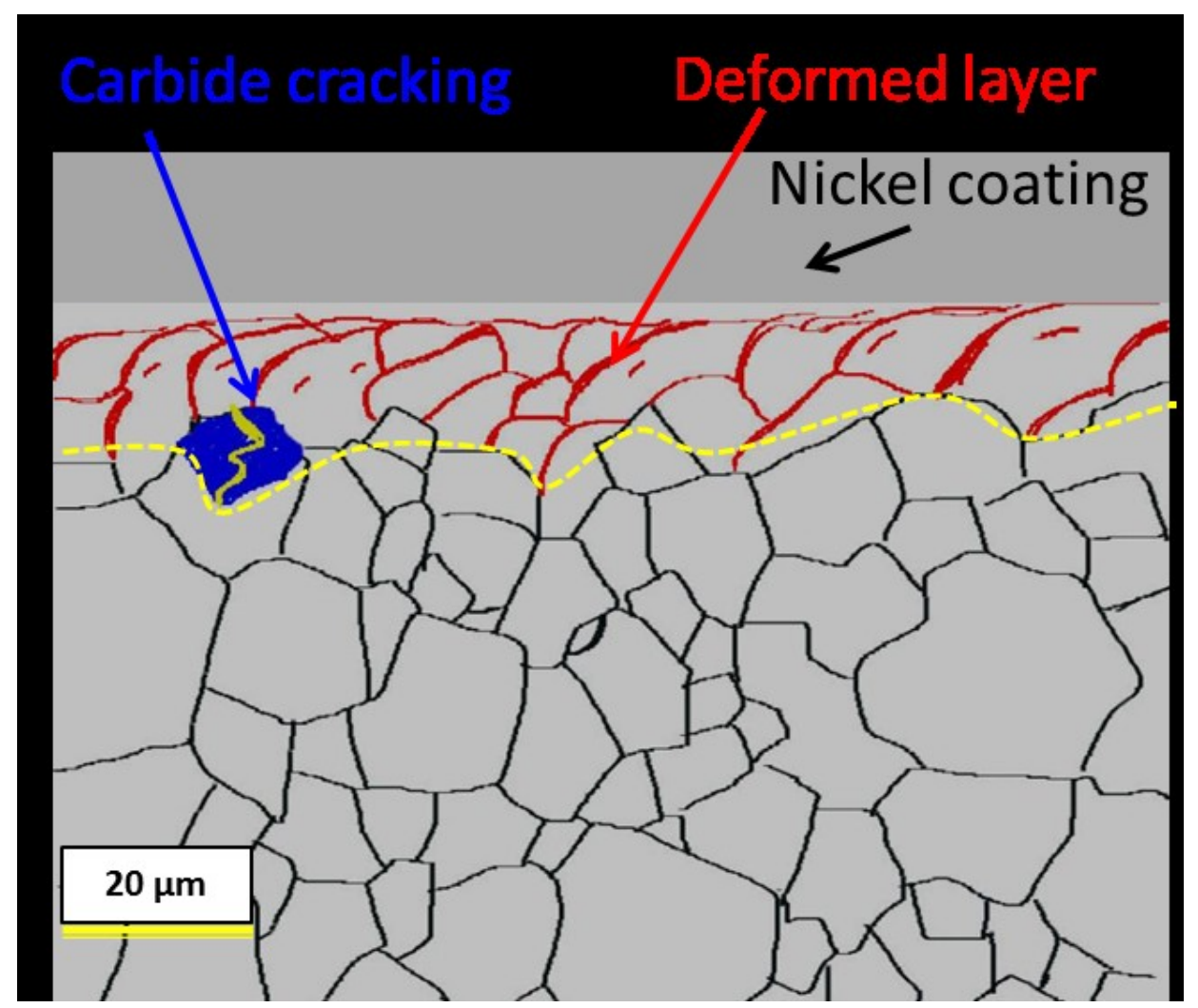

Fig. 8 Method used to characterize the depth of deformed layer using laser microscope 


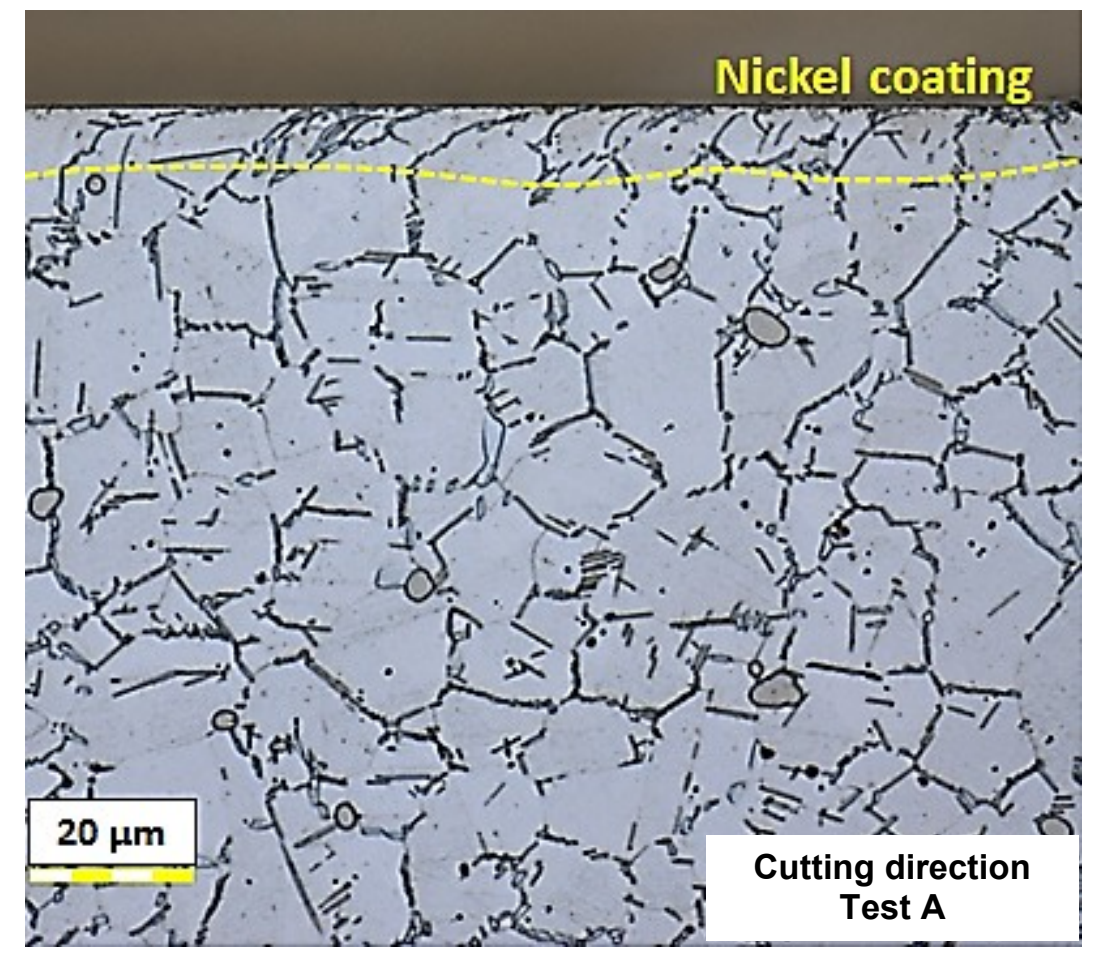

(a)

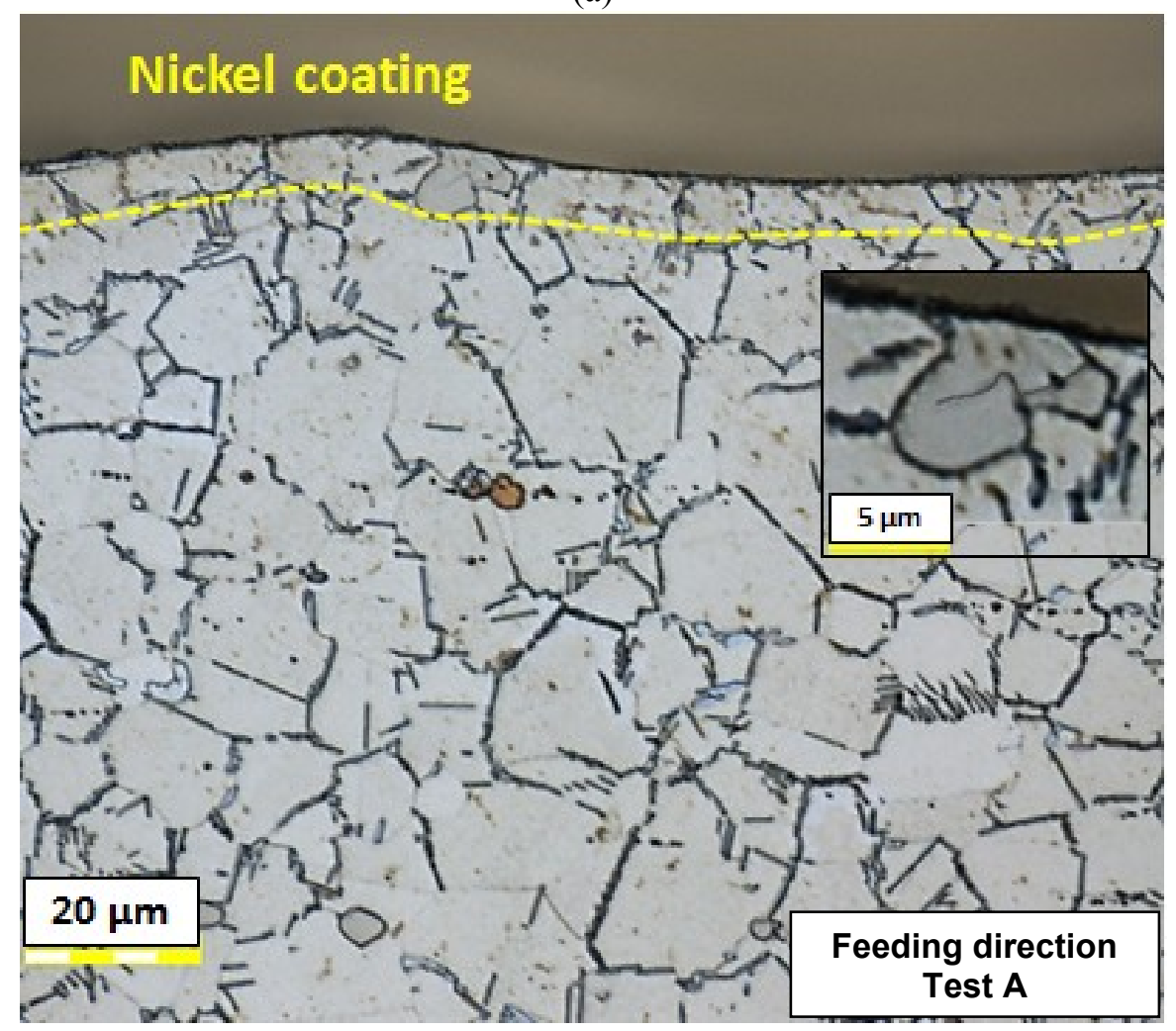

(b) 


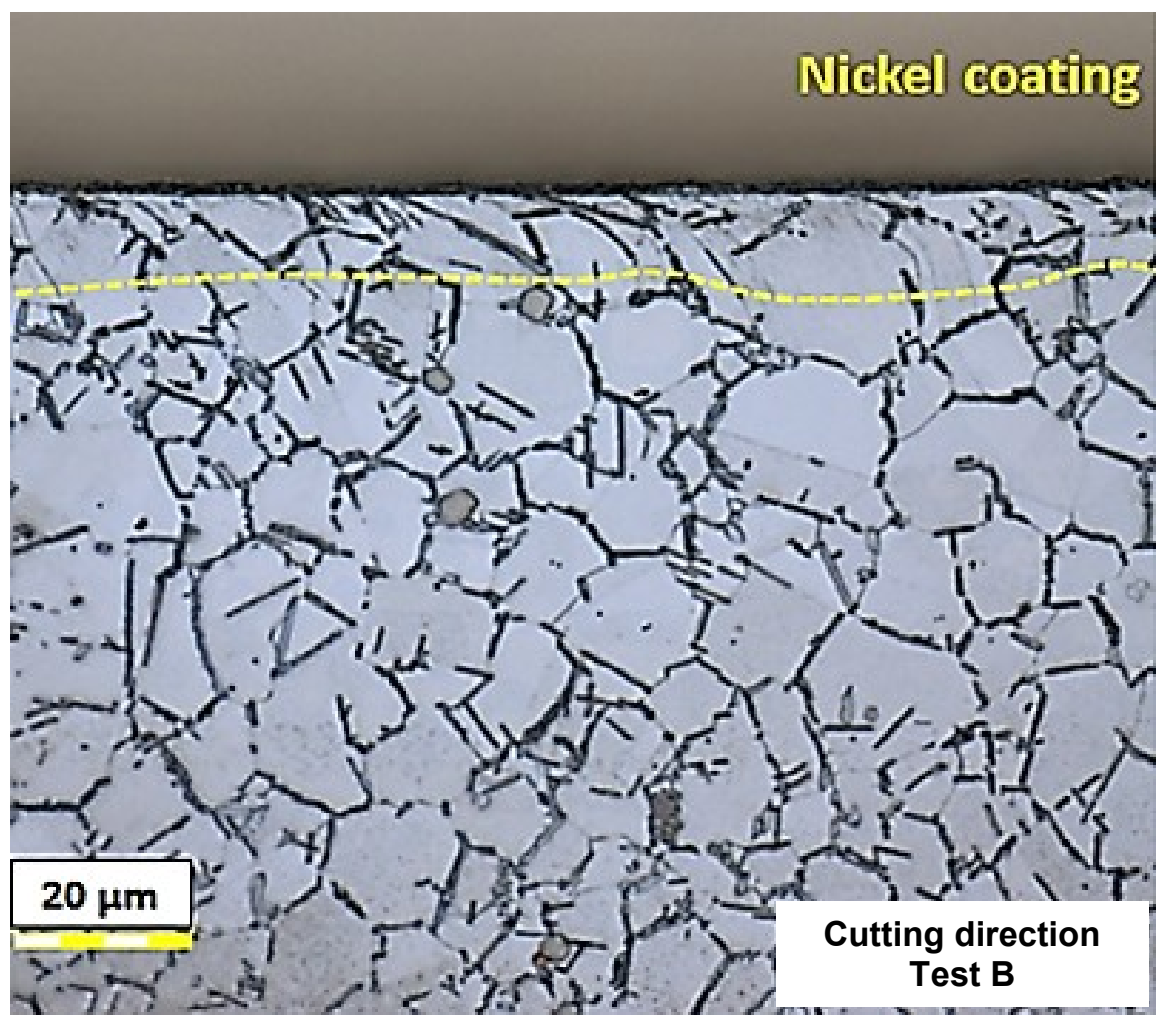

(c)

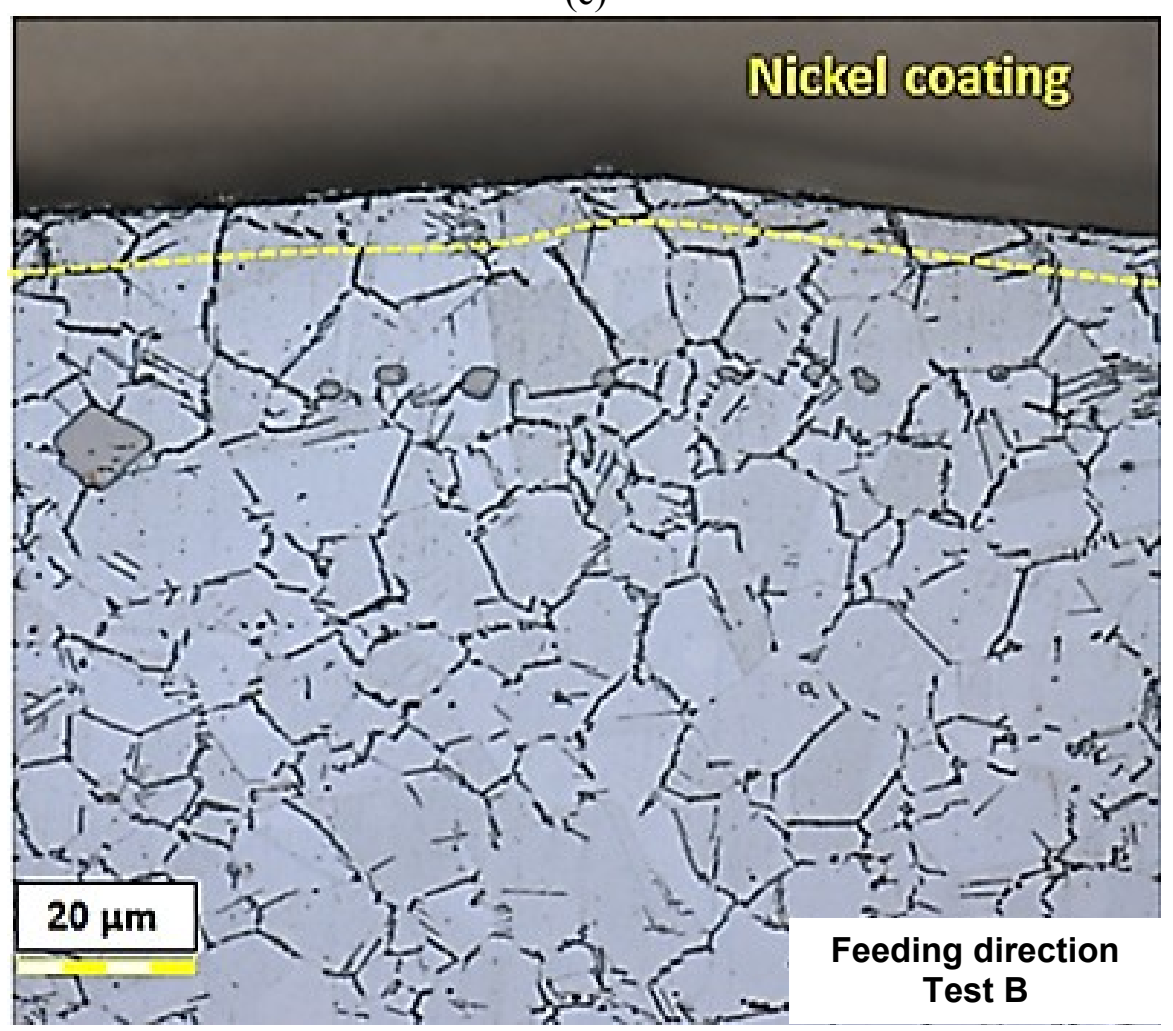

(d) 


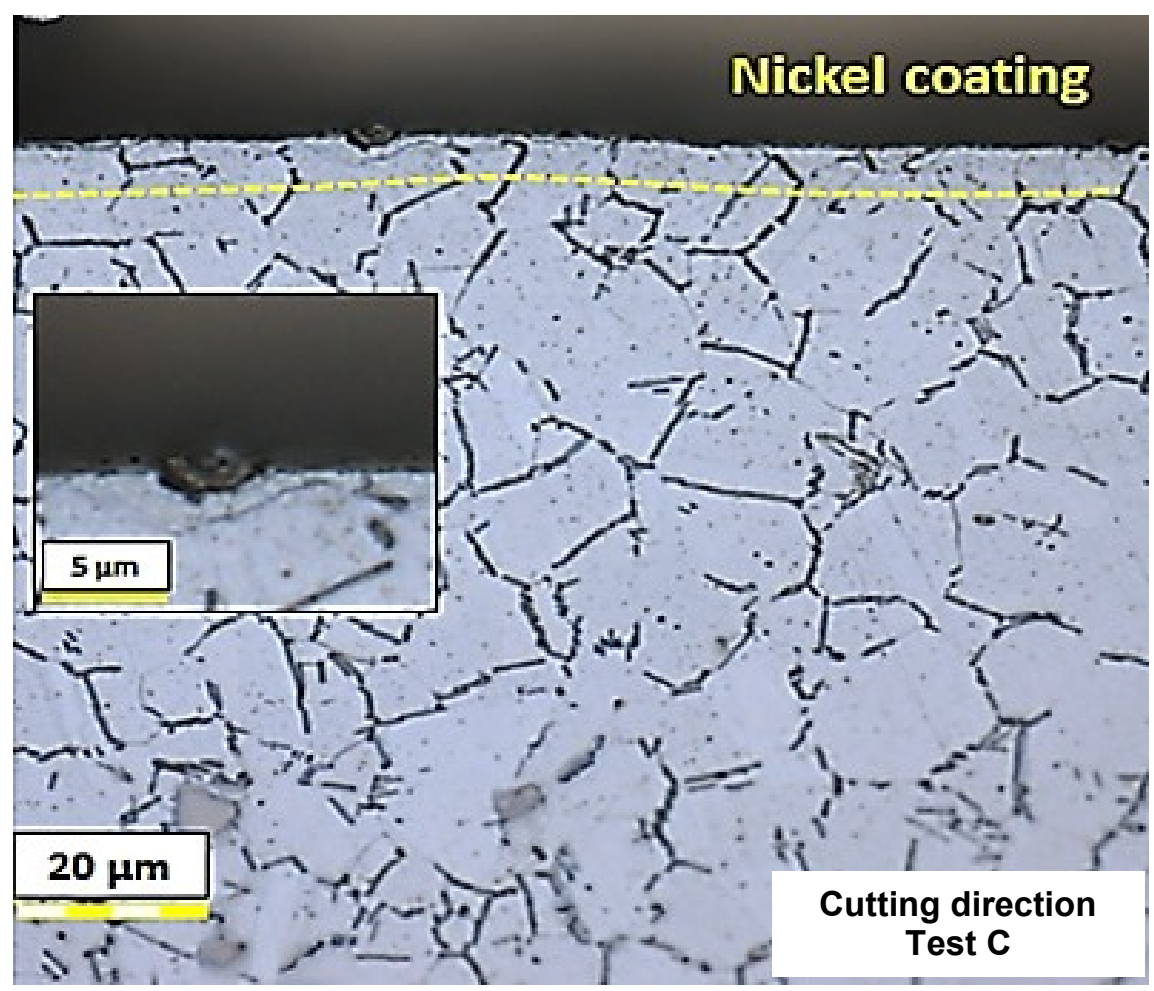

(e)

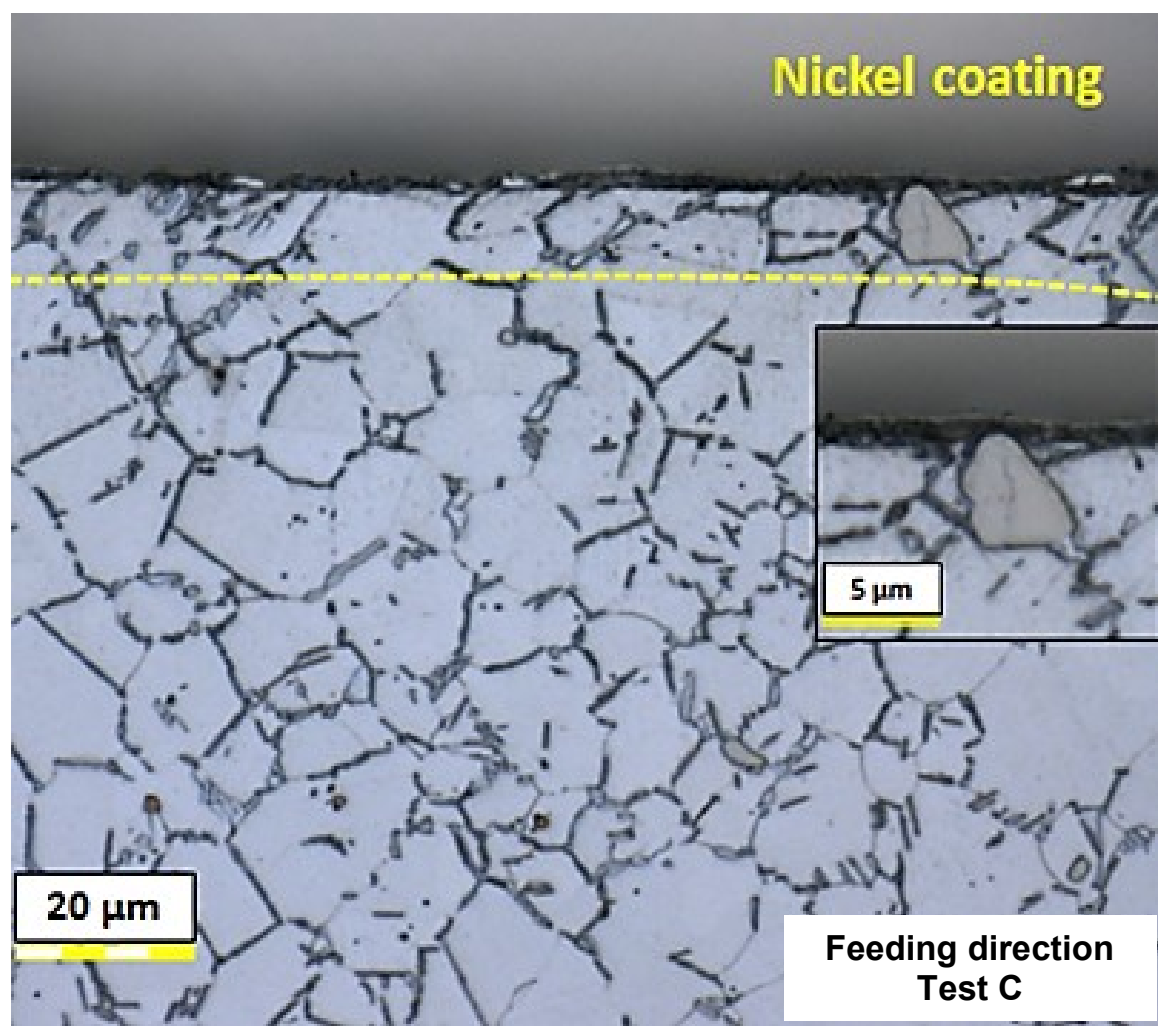

(f)

Fig. 9 Localisation of the deformed layers for the different tests: (a) cutting direction test A, (b) feeding direction test $\mathrm{B}$, (c) cutting direction test $\mathrm{B}$, (d) feeding direction test $\mathrm{B}$, (e) cutting direction test $\mathrm{C}$ and ( $\mathrm{f}$ ) feeding direction test $\mathrm{C}$ 


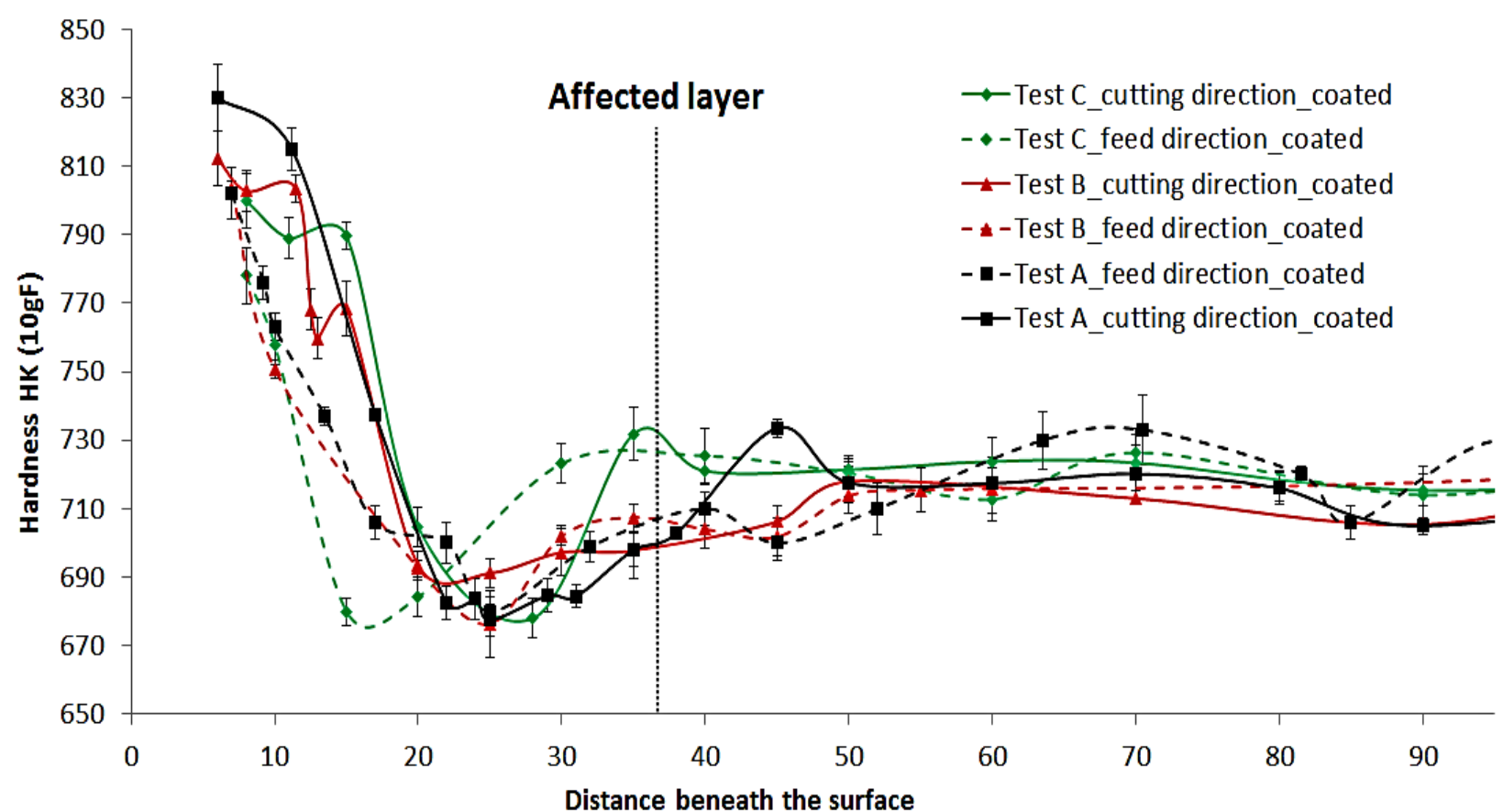

Fig. 10 Evolution of the knoop microhardness beneath the machined surface for the tests A, B and C: Dashed lines (feeding direction) and continuous lines (cutting direction)

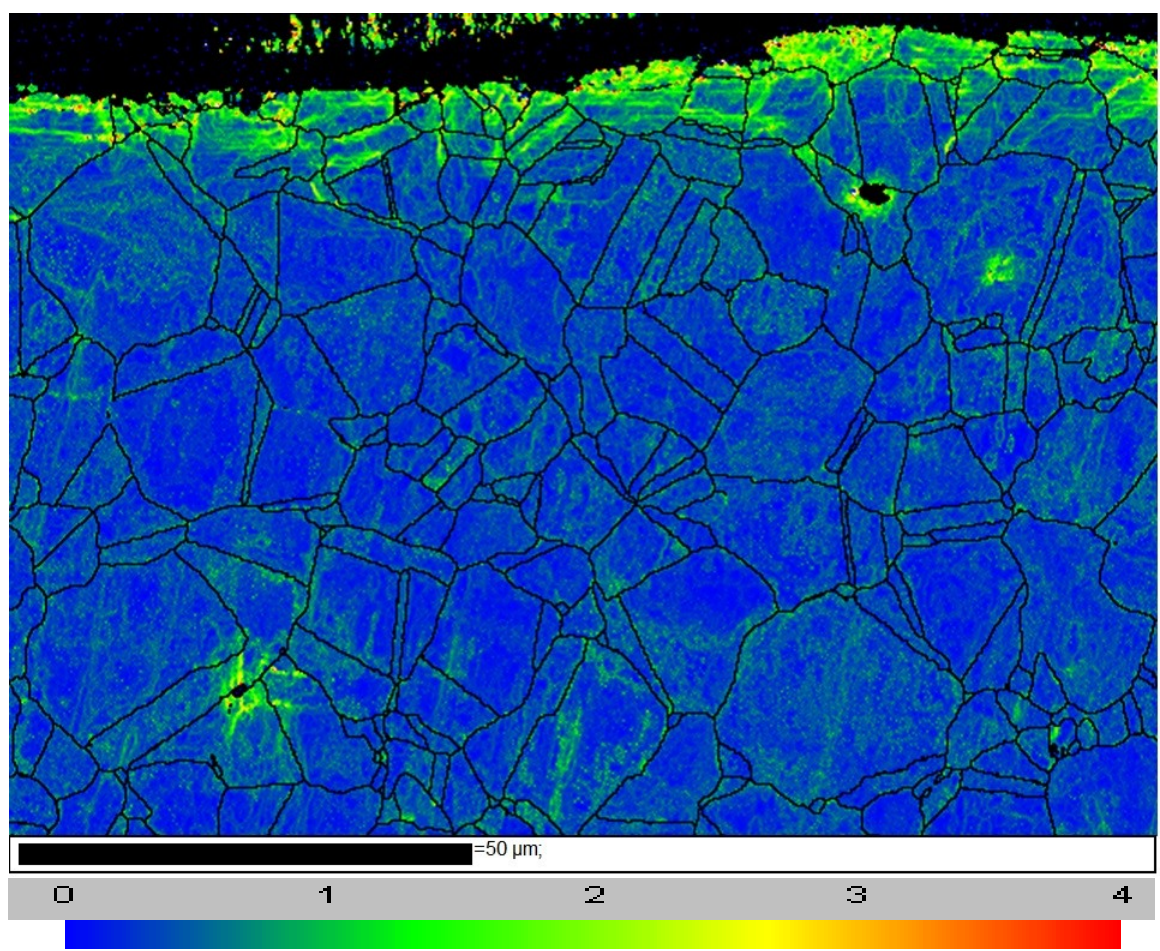

(a) 


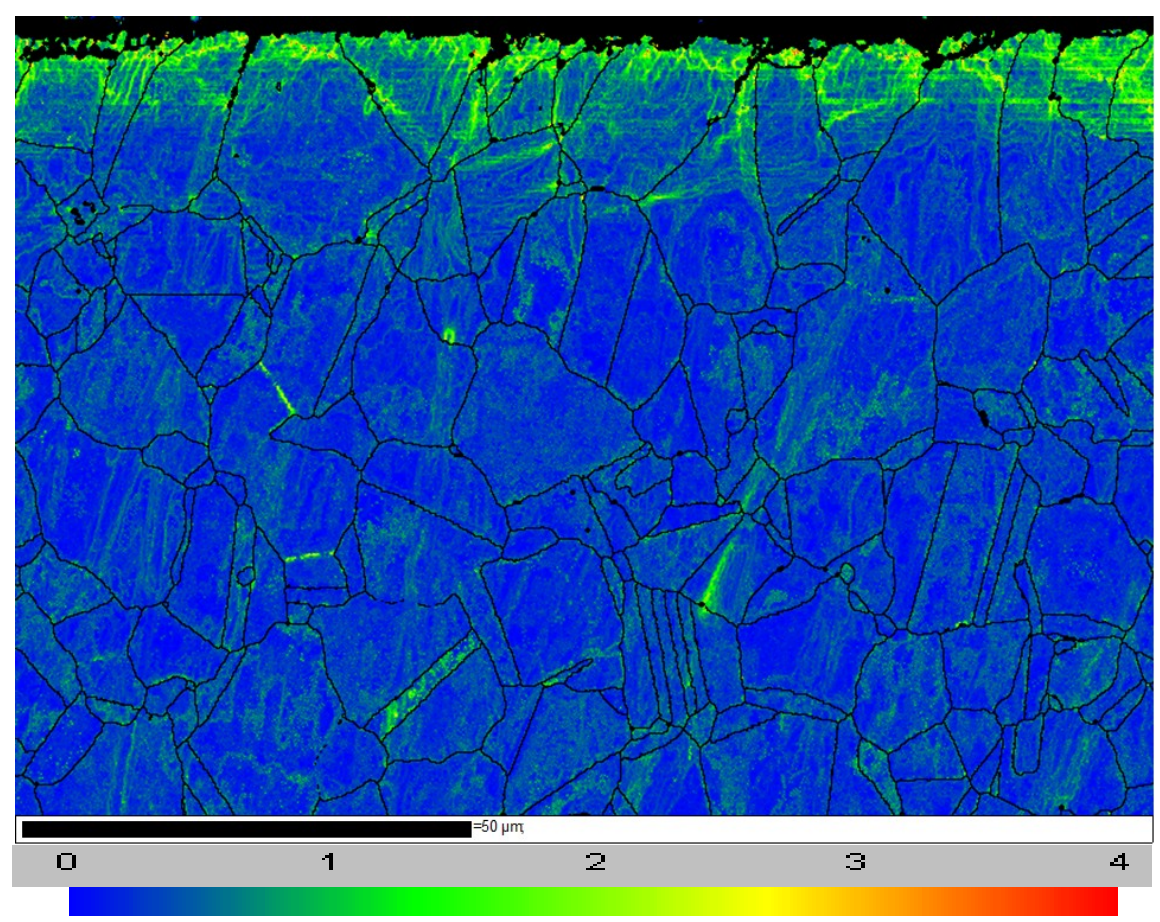

(b)

Fig. 11 Local misorientation in the surface and subsurface layer for the Inconel 718 machined for the test A: (a) following the feeding direction, (b) following the cutting direction. An area in green and red are highly deformed $\left(2^{\circ}\right.$ or more), and an area with low deformation is in blue 